\title{
ANALISIS BIAYA PENEBANGAN PADA HUTAN JATI RAKYAT DI KABUPATEN BONE
}

\author{
Felling Cost Analysis on Community Teak Forest Bone Regency
}

A. Mujetahid

\begin{abstract}
Community teak forest in Bone Regency was $\pm 4,220$ ha in wide, spreading in Amali, Ulaweng, Bengo, Mare, Tonra, Kahu, Salomekko, Ajangale, Dua Boccoe, Lamuru, Tellulimpoe, Lappariaja, Libureng, Palakka, Bontocani and Ponre Subdistricts. The descriptive method was used to describe and clarify felling activities of community teak forest yield. The quantitative approach was conducted by recording and analyzing the data such as potency, length, diameter, volume, working time, productivity, cost, etc. The study was aimed to felling cost $\mathrm{m}^{-3}$ with self-management was cheaper than by the piece, namely Rp.298,712,8 and Rp. 471,159.90 with difference amounting of Rp 172,447.10 $\mathrm{m}^{-3}$, but collector-traders chose contract work because considering social aspect, chance and opportunity to get others teak.
\end{abstract}

Key words: community teak forest, felling, cost.

\section{PENDAHULUAN}

Kegiatan pemanenan hasil hutan merupakan salah satu kegiatan terpenting dalam pengelolaan dan pengusahaan hutan. Pemanenan hasil hutan merupakan usaha pemanfaatan kayu dengan mengubah tegakan pohon berdiri menjadi sortimen kayu bulat dan mengeluarkannya dari hutan untuk dimanfaatkan sesuai peruntukannya. Adapun tujuan dari pemanenan hasil hutan yaitu memaksimalkan nilai kayu, mengoptimalkan pasokan kayu industri, meningkatkan kesempatan kerja serta mengembangkan ekonomi regional. Maksimalnya nilai hutan dapat dinilai dari jumlah produksi dan mutu kayu yang tinggi serta tegakan sisa bernilai tinggi pula.

Kegiatan pemanenan yang selama ini dilakukan, masih belum sepenuhnya mencerminkan tingkat efisiensi. Hal ini dapat dilihat dari tingginya biaya pemanenan. Efisiensi biaya pemanenan hasil hutan erat kaitannya dengan efisiensi biaya pada setiap tahapan pemanenan hasil hutan dan efisiensi pemanfaatan hasil tebangan. Makin tinggi tingkat efisiensi penebangan kayu, maka limbah yang terjadi makin kecil. Dengan demikian biaya yang dikeluarkan per satuan volume dapat lebih rendah.

Biaya merupakan hal yang sangat penting untuk diperhitungkan secara cermat, karena semua langkah dan kebijakan yang diambil harus berpangkal pada

satu tujuan yaitu dapat memberi keuntungan. Dengan demikian, perhitungan biaya bertujuan untuk mengendalikan pembiayaan, perhitungan harga pokok dan penilaian efisiensi kerja setiap kegiatan. Elias (1987) menyatakan bahwa faktor-faktor yang mempengaruhi biaya pemanenan hasil hutan berupa kayu meliputi ukuran, berat, kepadatan, jumlah pohon per satuan luas, jarak angkut, topografi, efisiensi jumlah tenaga, peraturan yang membatasi, seperti jumlah jam kerja per hari, keselamatan tenaga kerja, asuransi serta biaya penyediaan dan efisiensi alat.

Analisis biaya penebangan didasarkan pada data produktivitas kerja serta biaya yang dikeluarkan untuk melaksanakan pekerjaan. Dalam penelitian ini, jenis biaya diklasifikasikan ke dalam dua kelompok yaitu biaya mesin dan usaha. Biaya mesin adalah penjumlahan biaya tetap dan variable, sementara biaya usaha adalah penjumlahan antara biaya mesin dengan upah operator dan pembantuya. Biaya tetap 
meliputi biaya yang dikeluarkan untuk pembelian alat, penyusutan, bunga, pajak, asuransi dan semua biaya yang sifatnya tetap. Sedangkan biaya variabel meliputi pemeliharaan, perbaikan, bahan bakar, pelumas dan biaya lainnya yang sifatnya tergantung kepada beroperasinya alat.

Berdasarkan uraian tersebut di atas, maka tujuan yang ingin dicapai dalam penelitian ini adalah menganalisis besarnya biaya penebangan kayu jati rakyat di Kabupaten Bone antara pengelolaan secara swakelola dengan borongan.

\section{METODE PENELITIAN}

Penelitian ini dilaksanakan pada bulan Mei sampai bulan Juli 2009 di hutan jati rakyat Kabupaten Bone. Jenis peralatan yang digunakan antara lain roll meter $(50 \mathrm{~m})$ dan roll meter $(5 \mathrm{~m})$, kalkulator, tally sheet dan alat tulis menulis. Bahan yang digunakan serta dokumen yang menjadi acuan dan atau bahan komparasi meliputi hutan jati rakyat yang ditebang, ljin Pemanfatan Kayu Tanah Milik (IPKTM) yang telah dikeluarkan oleh Pemda Kabupaten Bone dan perda yang terkait dengan pemanfaatan hutan jati rakyat

\section{Metode pengumpulan data}

Pengumpulan data biaya pemanenan dilakukan dengan mencatat dan menghitung semua variabel yang terkait dengan pengeluaran biaya baik langsung maupun tidak langsung seperti: biaya investasi alat, suku bunga, asuransi, pajak, pemeliharaan, perbaikan, upah per sortimen dan atau per $\mathrm{m}^{3}$, penggunaan bahan bakar dan harga bahan bakar per liter, penggunaan pelumas dan harga pelumas per liter, umur ekonomis alat, waktu kerja penebangan, nilai sisa peralatan, volume tebangan dan lain-lain. Data ini dikumpulkan melalui pengamatan, pengukuran dan wawancara.

\section{Metode analisis data}

Biaya pemanenan ini dihitung dengan menggunakan formulasi FAO (1992) dengan persamaan sebagai berikut:

\section{a) Biaya tetap penebangan}

(1) Penyusutan dihitung dengan menggunakan rumus:

$$
D=\frac{M-R}{N \times t}
$$

Dimana :

$D=$ Penyusutan (Rp/jam)

$M=$ Investasi alat $(\mathrm{Rp})$

$\mathrm{R}=$ Nilai sisa alat pada akhir umur ekonomis $10 \%$ (Rp)

$\mathrm{N}=$ Umur ekonomis alat (tahun atau jam)

$\mathrm{t}=$ Waktu kerja alat dalam setahun (jam/tahun)

(2) Bunga modal dihitung dengan menggunakan rumus:

$B=\frac{\left(\frac{(M-R)(N+1)}{2}+R\right) x 0,0 p}{N x t}$

Dimana :

$B=$ Bunga modal (Rp/jam)

$0,0 p=$ Suku bunga/tahun $(18 \%)$

(3) Pajak

Besarnya pajak yang diperhitungkan adalah $5 \%$ dari nilai investasi alat dengan menggunakan rumus:

$P j=\frac{\left(\frac{(M-R)(N+1)}{2 N}+R\right) \times 0,05}{t}$

Dimana: $\mathrm{Pj}=$ Pajak (Rp/jam)

(4) Asuransi

Besarnya asuransi yang diperhitungkan adalah $5 \%$ dari nilai investasi alat dengan menggunakan rumus:

$P j=\frac{\left(\frac{(M-R)(N+1)}{2 N}+R\right) \times 0,05}{t}$

Dimana :

As $\quad=$ Asuransi (Rp/jam)

Jumlah biaya tetap (BT) dalam satuan Rp/jam dihitung dengan rumus:

$$
B T=D+B+P j+A s
$$


b) Biaya variabel penebangan

(1) Pemeliharaan (PIh)

Pemeliharaan dimaksudkan sebagai upaya untuk menjaga keragaan alat yang dihitung dengan membagi besarnya biaya yang dikeluarkan selama satu tahun dengan jam kerja peralatan per tahun sehingga diperoleh rata-rata biaya pemeliharaan per jam.

(2) Perbaikan (Prb)

Perbaikan dimaksudkan sebagai upaya untuk memulihkan peralatan yang rusak agar dapat dipergunakan kembali. Besarnya biaya yang dikeluarkan selama satu tahun dibagi dengan jam kerja peralatan per tahun sehingga diperoleh rata-rata biaya perbaikan per jam.

(3) Bahan bakar (Bbk)

Biaya pemakaian bahan bakar didasarkan kepada pengamatan langsung di lapangan dengan menghitung jumlah pemakaian (liter) setiap pohon yang ditebang. Biaya bahan bakar dihitung dengan rumus sebagai berikut:

$B b k=\frac{\text { Jumlah pemakaian BBK } x \text { Harga } / l}{\text { Waktu Terbang }}$

Dimana :

Bbk = Biaya bahan bakar (Rp/jam)

Selanjutnya dihitung rata-rata biaya pemakaian bahan bakar per pohon sebagai berikut:

$$
\overline{B b k}=\frac{\sum B b k}{n}
$$

Dimana :

$\overline{B b k}=$ Rata-rata biaya bahan bakar (Rp/jam)

$\mathrm{N}$ = Jumlah pohon ditebang (batang)

(4) Pelumas (PIm)

Biaya pelumas (Rp/jam) dihitung dari semua biaya yang dikeluarkan dibagi dengan jumlah jam kerja alat selama periode penggunaan.

Jumlah biaya variabel dihitung dengan rumus sebagai berikut:

$$
B V=P l h+P r b+B b k+P I m
$$

Dimana :

$\mathrm{BV}=$ Jumlah biaya variabel (Rp/jam)

$\mathrm{Plh}=$ Biaya pemeliharaan (Rp/jam)
Prb = Biaya perbaikan (Rp/jam)

Bbk = Biaya bahan bakar (Rp/jam)

$\mathrm{PIm}=$ Biaya pelumas (Rp/jam)

(5) Biaya mesin penebangan

Biaya mesin penebangan dihitung dengan menggunakan rumus:

$$
\mathrm{Bm}=\mathrm{BT}+\mathrm{BV}
$$

Dimana :

$\mathrm{Bm}=$ Biaya mesin penebangan (Rp/jam)

(6) Upah tenaga kerja (Up)

Upah tenaga kerja penebangan dapat dihitung dengan sistem borongan menurut volume tebang maupun panjang batang. Sistem upah yang digunakan adalah sistem upah borongan per volume tebang $\left(\mathrm{Rp} / \mathrm{m}^{3}\right)$. Untuk mendapatkan upah (Rp/jam), maka dibagi dengan jumlah jam kerja.

\section{c) Biaya usaha penebangan}

Biaya usaha penebangan adalah antara biaya mesin dengan upah.

\section{d) Biaya produksi penebangan}

Biaya produksi penebangan dihitung dengan rumus sebagai berikut:

$$
B P r=\frac{B \text { usaha }}{\text { Ptp }}
$$

Dimana :

$$
\begin{array}{ll}
\mathrm{BPr} & =\text { Biaya produksi }\left(\mathrm{Rp} / \mathrm{m}^{3}\right) \\
\text { B usaha } & =\text { Biaya usaha penebangan }\left(\mathrm{Rp} / \mathrm{m}^{3}\right) \\
\text { Ptp } & =\text { Produktivitas penebanga }\left(\mathrm{m}^{3} / \mathrm{jam}\right)
\end{array}
$$

\section{HASIL DAN PEMBAHASAN}

\section{Biaya Penebangan}

Kegiatan penebangan pada semua lokasi penebangan dilakukan secara mekanis dengan menggunakan chainsaw stihl 70 . Chainsaw tersebut adalah milik operator atau tidak disewa, karena biasanya operator chainsaw juga sebagai pemilik alat, sehingga besarnya biaya tetap yang dikeluarkan adalah hasil perhitungan biaya penyusutan, bunga modal, asuransi, pajak dan bukan sewa alat. Operator dibantu oleh helper dan upah helper juga menjadi tanggung jawab pemilik. 
Hasil pengamatan dan wawancara dengan operator chainsaw dan pengusaha kayu jati rakyat di lapangan diperoleh bahwa sistem pengupahan yang disepakati oleh keduanya adalah upah borongan yaitu dihitung berdasarkan jumlah potongan sortimen (bantalan, gelondongan) dikali dengan upah setiap potongan yaitu $R p R p$ 5.000- Rp 7.000,untuk sortimen berbentuk bantalan dan Rp 1.500,- 3.000,- kayu gelondongan. Biaya tersebut termasuk upah operator, helper, biaya tetap dan operasional peralatan. Berbeda halnya dengan perhitungan biaya dengan sistem swakelola yaitu kegiatan pemanenan dilakukan sendiri oleh pembeli/pengusaha terhadap jati rakyat yang telah dibeli dalam bentuk tegakan berdiri. Perhitungan biayanya menggunakan formulasi seperti yang diuraikan pada metode penelitian. Selisih antara biaya penebangan dengan sistem upah borongan dan swakelola merupakan keuntungan atau kerugian bagi pengusaha/pembeli terhadap kegiatan penebangan yang dilakukan.

Perhitungan biaya penebangan tersebut tidaklah sekedar menghitung biaya yang telah dikeluarkan pada periode yang lalu, tetapi justru dengan data terdahulu itulah dapat digunakan untuk menganalisa besarnya biaya yang akan dikeluarkan pada periode akan datang dalam kaitannya dengan optimalisasi pemanfaatan kayu. Dengan demikian perhitungan biaya penebangan ini dapat membantu dalam

pengambilan keputusan, seperti sistem pengupahan borongan atau swakelola.

Komponen biaya penebangan yang dihitung terdiri atas biaya tetap yang meliputi biaya penyusutan, bunga modal, asuransi dan pajak. Sementara biaya variable meliputi biaya pemeliharaan, perbaikan, bahan bakar, pelumas dan biaya kelengkapan peralatan penebangan (kikir, tali dll). Informasi terkait perhitungan biaya diperoleh dari hasil diskusi dengan operator chainsaw (harga alat, jam kerja, periode pergantian) dan studi pustaka terutama dalam perhitungan biaya tetap (nilai sisa alat, suku bunga, umur ekonomis alat) serta upah operator dan pembantunya.

Dengan diketahuinya biaya mesin dan usaha chainsaw, maka biaya penebangan per $\mathrm{m}^{3}$ dapat dihitung dan hasilnya seperti yang disajikan pada Tabel 1. Data yang disajikan pada tabel tersebut memberikan gambaran detail tentang uraian biaya dan masa pakai peralatan serta jenis suku cadang yang sering mengalami kerusakan dan perlu diperbaiki maupun yang merupakan bagian dari pemeliharaan rutin terhadap delapan operator chainsaw. Kedelapan operator chainsaw tersebut memiliki pengalaman kerja, umur chainsaw dan lokasi tebangan yang berbeda, sehingga produktivitas dan biaya per $\mathrm{m}^{3}$ yang diperoleh juga berbeda-beda.

Hasil perhitungan biaya penebangan pada hutan jati rakyat berdasarkan operator chainsaw di Kabupaten Bone disajikan pada Tabel 1.

\section{a. Biaya mesin}

Tabel 1, menunjukkan bahwa biaya mesin per jam pada kegiatan penebangan kedelapan operator chainsaw berkisar antara Rp 6.659,25Rp 8.749,54 dengan rata-rata $R p$ 7.682,73 yang terdiri atas biaya tetap sebesar Rp 970,83 $(12,64 \%)$ dan biaya variable $\mathrm{Rp} 6.711,90$ $(87,36 \%)$. Uraian masing-masing komponen biaya tersebut diuraikan berikut ini.

1) Biaya tetap

Biaya tetap merupakan komponen biaya yang secara keseluruhannya tetap dan tidak dipengaruhi jumlah produksi, kecuali biaya/unit selama umur ekonomis alat. Jumlah produksi akan berbanding terbalik dengan biaya per unit, sehingga semakin tinggi jumlah produksi maka biaya per unit semakin menurun.

Komponen biaya tetap dalam kegiatan penebangan antara lain biaya penyusutan chainsaw. Biaya penyusutan adalah biaya pembelian alat yang akan menyusut terusmenerus selama masa pakainya sebagai akibat dari keadaan alat yang semakin tua atau keausan. Biaya ini merupakan biaya terbesar dibandingkan dengan komponen biaya tetap

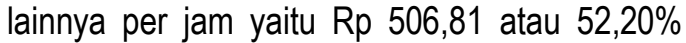
dari total biaya tetap dan $6,60 \%$ dari biaya mesin. Seperti yang dilaporkan Basari (2004) bahwa biaya penyusutan chainsaw yang digunakan pada kegiatan penebangan kayu bulat di Kalimantan Tengah adalah Rp 450/ jam. Hal ini lebih rendah dibandingkan dengan hasil penelitian ini, karena rata-rata harga chainsaw adalah Rp 5.631.250/unit, sedangkan Basari (2004) menggunakan chainsaw seharga $R p$ 5.000 .000 ,- 
Table 1. Felling Cost on Community Teak Forest Based on Chainsaw Operators in Bone Regency

\begin{tabular}{|c|c|c|c|c|c|c|c|c|c|}
\hline \multirow{2}{*}{$\begin{array}{c}\text { No } \\
\text {. }\end{array}$} & \multirow{2}{*}{ Uraian Biaya } & \multicolumn{8}{|c|}{ Biaya Penebangan Berdasarkan Operator Chainsaw (Rp/jam) } \\
\hline & & I & $\|$ & III & IV & V & $\mathrm{Vl}$ & VII & VIII \\
\hline I. & Biaya Mesin & & & & & & & & \\
\hline A. & Biaya Tetap Mesin & & & & & & & & \\
\hline 1. & Penyusutan & 585.00 & 567.00 & 472.50 & 450.00 & 495.00 & 472.50 & 472.50 & 540.00 \\
\hline 2. & Bunga Modal & 327.60 & 317.52 & 264.60 & 252.00 & 277.20 & 264.60 & 264.60 & 302.40 \\
\hline 3. & Asuransi & 104.00 & 100.80 & 84.00 & 80.00 & 88.00 & 84.00 & 84.00 & 96.00 \\
\hline 4. & Pajak & 104.00 & 100.80 & 84.00 & 80.00 & 88.00 & 84.00 & 84.00 & 96.00 \\
\hline \multicolumn{2}{|c|}{ Jumlah-A } & $1,120.60$ & $1,086.12$ & 905.10 & 862.00 & 948.20 & 905.10 & 905.10 & $1,034.40$ \\
\hline \multicolumn{10}{|c|}{ B. Biaya Variabel Mesin } \\
\hline 1. & Pemeliharaan & 120,83 & 125,69 & 167,36 & 121,53 & 125,69 & 146,53 & 167,36 & 146,53 \\
\hline 2. & Perbaikan & 925,01 & 425 & $1.243,75$ & 366,67 & $1.172,09$ & $1.136,26$ & $1.166,67$ & 486,67 \\
\hline 3. & Pelumas & 666.67 & 666.67 & 833.33 & 833.33 & 833.33 & 833.33 & 833.33 & 833.33 \\
\hline 4. & BBM & $4,583.33$ & $4,230.77$ & $5,500.00$ & $4,583.33$ & $4,400.00$ & $5,500.00$ & $5,000.00$ & $4,583.33$ \\
\hline 5. & Tali & 100.00 & 125.00 & 100,00 & 100.00 & 125.00 & 100.00 & 125.00 & 100.00 \\
\hline \multicolumn{2}{|c|}{ Jumlah-B } & $6,395.83$ & $5,573.13$ & $7,844.44$ & $6,004.86$ & $6,656.11$ & $7,716.11$ & $7,292.36$ & $6,212.36$ \\
\hline \multicolumn{2}{|c|}{ Biaya Mesin $(A+B)$} & $7,516.43$ & $6,659.25$ & $8,749.54$ & $6,866.86$ & $7,604.31$ & $8,621.21$ & $8,197.46$ & $7,246.76$ \\
\hline \multicolumn{10}{|c|}{ II. Upah Tenaga Kerja } \\
\hline 1. & Operator & $5,000.00$ & $5,000.00$ & $5,000.00$ & $5,000.00$ & $5,000.00$ & $4,375.00$ & $4,375.00$ & $4,500.00$ \\
\hline \multirow[t]{2}{*}{2.} & Helper & $3,125.00$ & $3,125.00$ & $3,125.00$ & $3,125.00$ & $3,125.00$ & $3,125.00$ & $3,125.00$ & $3,125.00$ \\
\hline & Jumlah-II & $8.125,00$ & $8.125,00$ & $8.125,00$ & $8.125,00$ & $8.125,00$ & $7.500,00$ & $7.500,00$ & $7.625,00$ \\
\hline \multicolumn{2}{|c|}{ Biaya Usaha (I+ II) } & $15,641.43$ & $14,784.25$ & $16,874.54$ & $14,991.86$ & $15,729.31$ & $16.121,21$ & $15.697,46$ & $14.871,76$ \\
\hline
\end{tabular}


Nugroho (2002), menyatakan bahwa
$\begin{aligned} & \text { penyusutan adalah metode untuk } \\ & \text { memperhitungkan: }\end{aligned}$

(a) Penurunan nilai pasar barang modal tetap yang berkaitan dengan penilaian asset (nilai buku) alat. Nilai buku adalah nilai beli alat dikurangi akumulasi depresiasi sampai dengan tahun yang bersangkutan.

(b) Alokasi biaya atas barang modal tetap yang digunakan selama waktu pakainya secara sistematis.

2) Biaya variabel

Biaya variabel adalah biaya persatuan unit produksinya tetap, tetapi akan berubah jumlah totalnya jika volume produksinya berubah. Jumlah produksi akan berbanding lurus dengan total biaya variabel, sehingga semakin tinggi jumlah produksi maka total biaya variabel semakin tinggi.

Komponen biaya variabel pada kegiatan penebangan adalah biaya pemeliharaan, perbaikan, pelumas, bahan bakar dan kelengkapan lainnya. Di antara biaya tersebut, biaya bahan bakar memberikan kontribusi sebesar $\operatorname{Rp~} 4.797,60$ atau $62,45 \%$ dari total biaya variable atau $30,78 \%$ terhadap biaya usaha mesin. Besarnya biaya bahan bakar disebabkan oleh penggunaan chainsaw yang terus menerus sejak persiapan penebangan, penebangan, pembersihan cabang dan ranting, pembagian batang dan pembuatan sortimen/bantalan yang membutuhkan waktu sekitar 23,703 menit, tingkat kekerasan kayu jati yang tinggi dibanding kayu hutan rakyat lainnya dan harga bahan bakar per liter yang lebih tinggi dibanding harga pertamina yaitu $\mathrm{Rp}$ $5.500,-$.

Selain biaya bahan bakar, biaya perbaikan dan pelumas memberikan kontribusi terbesar kedua dan ketiga yaitu masing-masing $\mathrm{Rp}$ 865,27,- per jam (12,89\%) dan Rp 791,67,- per jam (11,79\%). Perbaikan peralatan dimaksudkan sebagai upaya untuk memulihkan alat agar dapat dipergunakan kembali. Berbeda halnya dengan pelumas, yang digunakan untuk melumasi rantai agar licin.

Biaya pemeliharaan memiliki kontribusi terhadap biaya variabel sangat kecil yaitu $R p$ 140,19 ,- per jam atau hanya sekitar $2,09 \%$ atau $1,82 \%$ dari total biaya mesin. Biaya ini sangat kecil, tetapi rutin sesui dengan periode pemeliharaan. Pemeliharaan alat dimaksudkan sebagai upaya untuk menjaga keragaan (performance) alat.

\section{b. Biaya usaha}

Biaya usaha adalah biaya mesin ditambahkan dengan upah operator dan pembantunya. Selain bahan bakar, komponen biaya lainnya yang memberikan kontribusi biaya yang cukup besar dibandingkan dengan komponen biaya lainnya adalah upah yaitu sebesar Rp 7.906,25 per jam atau 50,72 \% dari total biaya usaha. Upah tidak termasuk ke dalam komponen biaya mesin, tetapi merupakan komponen biaya usaha secara keseluruhan.

\section{c. Biaya produksi penebangan}

Biaya produksi penebangan adalah biaya yang dikeluarkan untuk memproduksi kayu hasil tebangan per satuan unit. Dalam proses produksi penebangan, yang dapat dihitung sebagai biaya bukanlah seberapa banyak alatalat penebangan digunakan, melainkan seberapa lama waktu dari alat tersebut dimanfaatkan untuk memproduksi kayu hasil tebangan berupa sortimen atau gelondongan. Namun demikian untuk menentukan biaya produksi, waktu tidak dapat dimanfaatkan secara langsung sehingga perlu dikonversi ke dalam satuan biaya (Rp/jam). Waktu hasil konversi biaya dibandingkan dengan volume sortimen yang dihasilkan selama waktu tersebut sehingga diperoleh biaya produksi penebangan per satuan unit $\left(\mathrm{Rp} / \mathrm{m}^{3}\right)$ seperti disajikan pada Tabel 2.

Tabel 2 di atas menunjukkan bahwa besarnya biaya produksi penebangan per $\mathrm{m}^{3}$ kedelapan operator chainsaw sangat bervariasi yaitu berkisar antara $\mathrm{Rp} 14.712,33-\mathrm{Rp}$ $25.421,81$ dengan rata-rata $\mathrm{Rp} 18.908,08,-$. Variasi besarnya biaya usaha hasil konversi waktu antara operator chainsaw memiliki variasi yang relatif kecil dibandingkan dengan biaya produksi penebangan. Perbedaan biaya usaha per jam terendah dan tertinggi sebesar $\mathrm{Rp}$ $2.090,29$, sedangkan biaya produksi per $\mathrm{m}^{3}$ selisihnya mencapai Rp 10.709,48,-- 
Table 2. Contract Work and Cost Production of Felling Activity on Community Teak Forest, Bone Regency

\begin{tabular}{cccccccr}
\hline No. & Opcs & $\begin{array}{c}\text { Biaya } \\
\text { Usaha } \\
(\text { Rp/jam })\end{array}$ & $\begin{array}{c}\text { Ptp } \\
\left.\mathrm{m}^{3} / \mathrm{jam}\right)\end{array}$ & $\begin{array}{c}\mathrm{BPr} \\
\left(\mathrm{Rp} / \mathrm{m}^{3}\right)\end{array}$ & $\begin{array}{c}\text { Rata-rata } \\
\text { Volume } \\
\text { Sortimen } \\
\left(\mathrm{m}^{3} / \mathrm{batang}\right)\end{array}$ & $\begin{array}{c}\text { Jumlah } \\
\text { Batang } \\
(\text { Batang/ } \\
\left.\mathrm{m}^{3}\right)\end{array}$ & $\begin{array}{c}\text { Biaya } \\
\text { Borong }(\mathrm{Rp} / \\
\left.\mathrm{m}^{3}\right)\end{array}$ \\
\hline 1. & $\mathrm{I}$ & $15.641,43$ & 0,671 & $23.310,63$ & 0,0454 & 22,0053 & $132.031,6$ \\
2. & II & $14.784,25$ & 0,994 & $14.873,49$ & 0,0443 & 22,5799 & $135.479,6$ \\
3. & III & $16.874,54$ & 0,883 & $19.110,47$ & 0,0559 & 17,8928 & $107.357,1$ \\
4. & IV & $14.991,86$ & 1,019 & $14.712,33$ & 0,0753 & 13,2780 & $79.667,8$ \\
5. & V & $15.729,31$ & 0,817 & $19.252,52$ & 0,0398 & 25,1281 & $150.768,5$ \\
6. & VI & $16.121,21$ & 0,836 & $19.283,75$ & 0,0406 & 24,6443 & $147.866,0$ \\
7. & VII & $15.697,46$ & 1,026 & $15.299,67$ & 0,0602 & 16,6099 & $99.659,4$ \\
8. & VIII & $14.871,76$ & 0,585 & $25.421,81$ & 0,0336 & 29,7619 & $178.571,4$ \\
\hline \multicolumn{2}{l}{ Rata-rata } & $15.589,00$ & 0,854 & $18.908,08$ & 0,0494 & 21,4875 & $128.925,2$ \\
\hline
\end{tabular}

Keterangan:

Opcs : Chainsaw operators

Ptp : : Felling productivity $\left(\mathrm{m}^{3} / \mathrm{jam}\right)$

$\mathrm{BPr} \quad$ : Felling production cost $\left(\mathrm{Rp} / \mathrm{m}^{3}\right)$

Hal ini memberikan gambaran bahwa besar kecilnya waktu hasil konversi biaya, tidak secara langsung menunjukkan besarnya kayu hasil tebangan yang dihasilkan, tetapi masih harus dibandingkan besarnya kayu tebangan yang dihasilkan. Dengan demikian biaya produksi sangat ditentukan oleh produktivitas setiap operator chainsaw, yaitu besarnya hasil tebangan yang dihasilkan dengan waktu yang digunakan. Olehnya itu, terdapat beberapa variasi hubungan antara waktu, biaya dan out put sebagai berikut:

1) Biaya usaha per siklus produksi besar dan volume kayu hasil tebangan per satuan waktu juga besar yaitu pada operator chainsaw III dan VI.

2) Biaya usaha per siklus produksi besar tetapi volume kayu hasil tebangan per satuan waktu kecil yaitu pada operator chainsaw I.

3) Biaya usaha per siklus produksi kecil tetapi volume kayu hasil tebangan per satuan waktu besar yaitu pada operator chainsaw II, IV dan VII.

4) Biaya usaha per siklus produksi kecil dan volume kayu hasil tebangan per satuan waktu kecil yaitu operator chainsaw VIII, sehingga menyebabkan biaya produksi penebangan menjadi lebih tinggi.

Biaya penebangan dengan chainsaw dapat lebih murah jika jumlah kayu yang ditebang lebih banyak dan tidak tersebar dengan menggunakan peralatan yang masih dalam umur ekonomis dengan operator yang berpengalaman seperti pada operator II, IV dan VI. Oleh karena itu penggunaan peralatan perlu dipikirkan secara matang. Biaya usaha dan produksi penebangan setiap operator chainsaw disajikan pada Gambar 1.

\section{KESIMPULAN}

Berdasarkan analisis terhadap hasil penelitian, maka dapat ditarik kesimpulan bahwa biaya pemanenan per $\mathrm{m}^{3}$ dengan sistem swakelola lebih murah dibandingkan borongan yaitu sebesar Rp 298.712,8 dan Rp 471.159,9 dengan selisih sebesar Rp 172.447,1 per m³, tetapi pedagang pengumpul memilih sistem borongan karena pertimbangan aspek sosial, peluang dan kesempatan untuk mendapatkan kayu jati lainnya. 


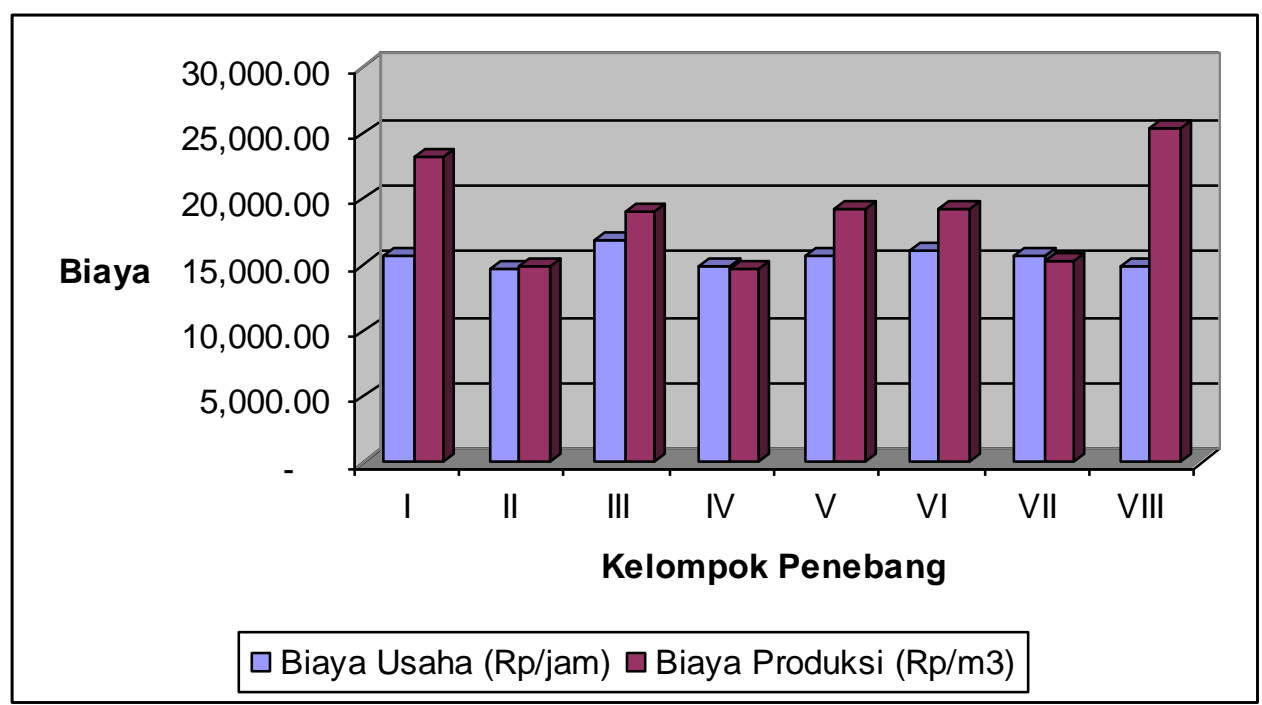

Figure 1. Felling Production and Effort Cost Histogram Based on Chainsawman Group

\section{DAFTAR PUSTAKA}

Basari. 2004. Analisis Biaya Pemanenan Kayu Bulat Sistem Kemitraan HPH-Koperasi Desa di Kalimantan Tengah. Jurnal Penelitian Hasil Hutan 22 (2):113-122.

Elias. 1987. Analisa Biaya Eksploitasi Hutan. Bogor: Fakultas Kehutanan Institut Pertanian Bogor.
FAO. 1992. Cost Control in Forest Harvesting and Road Construction. FAO Forestry Paper No. 99. FAO of the UN. Rome.

Nugroho, B., 2002. Analisis Biaya Proyek Kehutanan. Bogor: Yayasan Penerbit Fakultas Kehutanan IPB.

Diterima : 12 April 2010

\section{A. Mujetahid}

Lab. Pemanenan dan Pembukaan Wilayah Hutan

Jurusan Kehutanan, Universitas Hasanuddin

Kampus Tamalanrea, Jl. Perintis Kemerdekaan Km. 10, Makassar 90245

Telp./Fax. 0411-585917. Indonesia 